\title{
Decoding ClassDojo: psycho-policy, social-emotional learning, and persuasive educational technologies
}

\author{
Ben Williamson, Faculty of Social Sciences, University of Stirling, Stirling UK \\ ben.williamson@stir.ac.uk
}

Post-print version of article published as:

Williamson, B (2017): Decoding ClassDojo: psycho-policy, social-emotional learning and persuasive educational technologies, Learning, Media and Technology:

http://dx.doi.org/10.1080/17439884.2017.1278020

\begin{abstract}
ClassDojo is one of the world's most successful educational technologies, currently used by over 3 million teachers and 35 million children globally. It reinforces and enacts emerging governmental 'psychopolicies' around the measurement and modification of children's social and emotional learning in schools. This article focuses specifically on the ways ClassDojo facilitates psychological surveillance through gamification techniques, its links to new psychological concepts of 'character development,' 'growth mindsets' and 'personal qualities,' and its connections to the psychological techniques of Silicon Valley designers. Methodologically, the research mobilizes network analysis to trace the organizational, technical, governmental and scientific relations that are translated together and encoded in the ClassDojo app. Through its alignment with emerging education psycho-policy agendas around the measurement of non-cognitive learning, ClassDojo is a key technology of 'fast policy' that functions as a 'persuasive technology' of 'psycho-compulsion' to reinforce and reward student behaviours that are aligned with governmental strategies around social-emotional learning.
\end{abstract}

Keywords behaviour change, ClassDojo, fast policy, growth mindsets, social-emotional learning

ClassDojo is a globally popular classroom management application that reinforces and enacts emerging governmental policies around the psychological surveillance, measurement and modification of children's social and emotional learning in schools. Launched in 2011 by two British entrepreneurs with financial and technical support from Silicon Valley venture capital sources, ClassDojo has since become one of the world's most successful educational technologies. According to its website, by 2016 it was being used by over 3 million teachers and 35 million children in 180 countries, primarily in elementary and primary schools (https://www.classdojo.com/). ClassDojo is a free mobile app that allows teachers to award 'positive behaviour' points for individual children's behaviour and participation in the classroom. The founders of ClassDojo, Sam Chaudhary and Liam Don, were both educated in the UK (Chaudhary earned a degree in economics from Cambridge and Don a degree in computer science from Durham University), but moved to Silicon Valley in their early 20s to develop the idea after successfully applying to the educational technology development program Imagine K12. Launched as a beta product in 2011 and as a full platform in 2013, by early 2016 the app had attracted tens of millions of dollars in venture capital funding, and during 2016 new 'school- 
wide' features were launched that have enabled it to become a platform for school communications and for recording and storing students' behavioural data (Empson 2013; Kolodny 2016). The business magazine FastCompany listed ClassDojo as one of the 10 most innovative education companies in 2013, and in 2015 it won the Crunchie award for best education startup from the TechCrunch awards. Also in 2016, ClassDojo positioned itself as a broadcast platform for educational content, which included a series of video animations based around the concept of 'growth mindsets' from positive psychology. Reportedly viewed more than 15 million times within six months of being launched, according to its website, the growth mindset series is demonstrative of how ClassDojo has become a platform for the rapid and transnational diffusion of new forms of psychological expertise - and its practical techniques of monitoring, measuring and modifying behaviours and affects - into the practices of the classroom.

The argument developed in the article is that ClassDojo, through its alignment with emerging education policy agendas around the measurement of 'non-cognitive' or 'social-emotional' learning and wider governmental 'behaviour change' programs, is becoming a key technology of government, one that reinforces and rewards students for behaviours that are becoming the basis for emerging school accountability systems. By examining how ClassDojo is situated in policy agendas, I show how it acts as a technology of 'fast policy,' or 'the intensified and instantaneous connectivity of sites, channels, arenas, and nodes of policy development, evolution, and reproduction' (Peck \& Theodore 2015: 223). Recent studies of fast policy have shown that contemporary policy processes are increasingly transnational and 'encompass sprawling networks of human and nonhuman actors' such as websites, entrepreneurs, commercial companies, reports and scientists (Peck \& Theodore 2015: 3). The 'speeding up' of education policy specifically has been supported by the growth of technologies of data collection and analysis, which are seen to help to create insights into 'what works' and 'best practices' that can influence decision-making at fast pace (Lewis \& Hogan 2016). The claim in this article is that ClassDojo acts as part of a fast policy network related to social-emotional learning, speeding up the diffusion and enactment of new policy priorities that have their roots in behavioural science and psychological forms of expertise. In this sense, it instantiates within education new forms of 'psycho-policy' that emphasize the 'surveillance of psychological characteristics' and 'interventions intended to modify attitudes, beliefs and personality, notably through the imposition of positive affect' (Friedli \& Stearn 2015: 40). While it is of course not a novel claim that educational technologies enact government agendas, the close alignment of ClassDojo with emerging governmental priorities regarding children's social and emotional lives represents a contemporary entanglement of psychological expertise, commercial ed-tech, and policy priorities that amounts to an acceleration of governmental behaviour change programs in schools.

\section{Social-emotional learning}

The psychological sciences have long played a significant role in generating classifications by which children are measured and monitored. Through psychological techniques, children have been made visible and assessable through scales, charts, visual displays and other inscriptions relating to norms of posture and movement, personal habits, personality, and diverse forms of conduct. These have transformed the child through the 'scientific and technical imagination' into 
an 'object-child,' rendered in 'manipulable, coded, materialized, mathematized, two-dimensional traces, which may be utilized in any procedure of calculation' (Rose 1996: 112). ClassDojo, as detailed later, is a significant instantiation of psychological techniques that, for the past century, have been developed to surveil, codify, calculate, predict and maximize the mental and emotional functioning of the child through normative classifications (Popkewitz 2012).

Framing the recent popularity of ClassDojo is an emerging psychological agenda and policy priority concerned with the development of children's social and emotional skills, or what are variously described as 'non-cognitive' or 'non-academic' capacities and 'personal qualities' such as 'character,' grit,' 'resilience' and 'perseverance.' For example, in 2015 the Organization of Economic and Cooperation and Development (OECD) launched the report 'Skills for Social Progress: The Power of Social and Emotional Skills' as part of its Education and Social Progress program. The report emphasized the importance of social and emotional skills to children's future educational and labour market success and other social outcomes such as health and subjective well-being. It highlighted how 'important social and emotional skills are malleable during childhood and adolescence, allowing opportunities for policy makers, teachers and parents to provide the right learning environments to accompany them at those stages,' including by 'promoting strong relationships between educators (e.g. parents, teachers and mentors) and children' (OECD 2015: 3). Furthermore, the report contended that 'social and emotional skills can be measured meaningfully' and that 'such measures can be instrumental to help decision makers better assess children's current skill sets and their future needs, and thereby help teachers and parents to effectively adapt the pedagogy, parenting and learning environments accordingly' (OECD 2015: 3). Similarly, in 2016 the World Economic Forum (WEF) produced 'New Vision for Education: Fostering Social and Emotional Learning through Technology,' claiming 'social and emotional proficiency will equip students to succeed in the swiftly evolving digital economy,' and highlighting how digital technologies could be used to build 'character qualities' and 'enable students to master important social and emotional skills' (WEF 2016: 5).

Recently introduced policies in the US are now making children's social and emotional skills in schools into a significant governmental agenda (Zernike 2016). A report for the US Department of Education in 2013 has promoted a 'shift [in] educational priorities to promote not only content knowledge, but also grit, tenacity, and perseverance' (Schechtman et al. 2013: v). As a result, new psychological instruments have been developed to measure 'personal qualities' such as self-control, grit, character, growth mindsets, and many others (Duckworth \& Yeager 2015). With US schools now under pressure-following the introduction of the Every Student Succeeds Act in 2015-to provide measurable evidence of progress on the development of students' non-academic learning, this 'new accountability system is thought to be the largest effort to focus on and evaluate students' habits of mind' (Adams 2014). Such developments reinforce how psychological conceptions have had major impacts on many governmental policies, not least in relation to the management of children. In the UK, meanwhile, the government-funded Education Endowment Foundation has produced guidance on 'improving children's social and emotional skills' through strategies that 'improve the ways in which children interact with their peers, parents or other adults' and 'seek to improve behaviour or engagement throughout settings' (EEF 2016). 
In addition to its links to the governmentalization of psychological concepts, ClassDojo materializes a particular brand of contemporary educational thought as a direct product of Silicon Valley. Silicon Valley has recently developed significant interests in education, as demonstrated by its massive escalation in venture capital funding for educational technology startup companies and support for high-tech models of alternative schools (Williamson 2016). A distinctive political outlook underpins Silicon Valley's commitment to education. Duff (2016: 13) argues that Silicon Valley combines individualism, risk-taking, and the socially destabilizing potential of innovation. Those who subscribe to 'the Silicon Valley ideology' therefore see 'government as an investor rather than as a protector, arguing that the government's role is to invest in making people as awesome as possible' (Lee \& Ferenstein 2016). As Ferenstein (2015) notes, many Silicon Valley startup founders 'believe that the solution to nearly every problem is more innovation, conversation or education,' and are especially interested in education as a form of investment in human capacities and positive attitudes. As shall be shown, Silicon Valley is the epicenter for the emerging agenda around social and emotional learning, in particular through its links with Stanford University. As both a Silicon Valley product and a partner with Stanford University's own growth mindset research program, ClassDojo is a material example of how the distinctively technocratic political outlook of Silicon Valley now infuses the educational technology sector, in ways that reinforce the emerging governmentalization of psychological concepts regarding social and emotional learning.

\section{Networks and translations}

Methodologically, this study of ClassDojo is informed by a 'network analysis' approach developed in the field of education policy studies. Network studies follow the relationships, events, and exchanges between organizations and actors, their relations, activities, and the paths and connections that join-up these actors (Ball 2016: 2-3). I have employed aspects of network analysis such as tracing the links and relationships between the ClassDojo company and associated actors and organizations, and by following documentary connections and linkages between ClassDojo and other sources. This has involved closely examining the ClassDojo website, news releases, press coverage, and following its social media presence. In the literature on fast policy, researchers commit to 'following policies' as they evolve, mutate and 'become real' through discourses and technologies (Peck \& Theodore 2015: xxv). My approach is to follow ClassDojo as a specific technology which, framed by psychological, governmental and Silicon Valley discourses, is helping to translate, diffuse and enact the wider social and emotional learning policy agenda. Fenwick and Edwards (2010: 9) define 'translation' as 'what happens when entities, human and non-human, come together and connect' to 'form a chain or network of action and things, and these networks ... become stable and durable. At each of these connections, one entity has worked upon another to translate or change it to become part of a collective or network of coordinated things and actions.' Once a network has been stabilized into a particular object, 'like a black box it appears inevitable and immutable, while concealing all the negotiations that brought it into existence' and also disguising how it can 'transform, distort and modify' the various element of which it is composed (Fenwick \& Edwards 2010: 11). 
Translation has been conceptualized as a key technique of government. Miller and Rose (2008: 34-35) describe 'government at a distance' as the ways in which governmental aspirations and goals are translated through the work of allied actors into practices exercised at arms-length from main governmental centres:

\footnotetext{
It is, in part, through adopting shared vocabularies, theories and explanations that loose and flexible associations may be established between agents across time and space-Departments of State, pressure groups, academics, managers, teachers, employees, parents - while each remains, to a greater or lesser extent, constitutionally distinct and formally independent.
}

Mobilizing these ideas of translation, fast policy and government at a distance, I analyze how ClassDojo is constituted by a relatively stable network of affiliations between governmental authorities, psychological experts, Silicon Valley entrepreneurs, and classroom practitioners that have all been connected together, and become stabilized and maintained as a particular object with its own norms. As part of a network of actors formed through the translation and adoption of shared vocabularies, explanations and theories, ClassDojo is becoming a key black boxed technology of government at a distance, enabling the social and emotional learning agenda to gain traction through its enactment in schools. The rest of this article offers an original critical analysis that opens up the black box of ClassDojo and makes visible some of the networks, histories and translations that have made it into such a globally successful product and a key actor that is speeding up the diffusion of the social and emotional learning policy agenda.

\section{Psychological surveillance}

Though ClassDojo has been marketed in relation to positive psychological concepts such as growth mindsets and character development, the basic app at its core owes more to a much longer history of behaviourist psychology. ClassDojo was originally conceived and designed as a behaviour management tool for the classroom. In practice, the ClassDojo app can be operated on a variety of desktop and mobile platforms. The promotional video on the website shows it used on a smartphone and tablet, with the teacher awarding points on-the-move and in real-time. Each child in the system is represented by a cute avatar, a dojo monster, which can be customized by the user. The app allows teachers to award positive 'dojo' points under default categories of 'hard work,' 'participating,' 'helping others,' 'teamwork,' 'leadership,' and 'perseverance and grit'. Behavioural targets can be set for both individuals and groups to achieve positive goals. Teachers can also give 'warnings' or deduct points (classified by a 'needs work' icon). The awarding and deduction of points becomes a kind of data timeline, with teachers able to produce time series visualizations for each child to show their progress over time, or display relative progress against each other to a whole class as a leaderboard.

The design of ClassDojo reflects the recent trend of 'gamification' whereby many sorts of everyday activities have been reconfigured as a form of play and fun. Its avatars, visual leaderboards and points system make it seem more like a videogame than a behaviour management tool. It also invites children to 'game' the system by treating positive classroom behaviour as something that can be exchanged for points, rewards and competitive positioning. In this respect, ClassDojo turns classroom behaviour into a quantifiable source of value for children to use as a public display of their compliance with classroom norms and expectations. 
For Whitson (2013) gamification inevitably also facilitates surveillance, because 'digitization makes it much easier to collect player data and metrics, and then, as a process of function creep, to use this data in new and innovative ways, such as ... subtly shaping users' in-game desires and behaviours.' ClassDojo facilitates forms of ludic surveillance involving teachers monitoring children via a gamified interface, but also children measuring and valuing themselves and their classmates through visualizations of their behavioural data.

In addition, parents are able to receive messages, photographs and video content from the classroom posted by teachers, and can login to the website to see their child's points in visualized formats. In March 2016, ClassDojo announced 'school-wide' features to allow whole schools, not just individual teachers, to sign up for accounts, which allow 'teachers and school leaders to safely share photos, videos, and messages with all parents connected to the school at once, replacing cumbersome school websites, group email threads, newsletters, and paper flyers' (http://www.prnewswire.com/news-releases/classdojo-expands-from-classrooms-to-schools300242206.html). This function creep positions ClassDojo as a behavioural surveillance platform that extends beyond the classroom to the school leader's office and out to the domestic space of the home.

As a behaviour surveillance and management tool, ClassDojo represents continuities with historical behaviourist techniques that have sought to observe and modify the actions of children. Burger (2015: 54) describes it as based on the behaviourist theory of 'operant conditioning' associated with B.F. Skinner, asserting that 'ClassDojo was designed as a classroom management tool designed to reinforce students' behaviors in order to get them to repeat behaviors that earn positive reinforcements and refrain from ones that earn negative reinforcements.' The development of machines to reward children for positive learning behaviour goes back at least as far as the 1920s, with innovative 'teaching machines' that would dispense candy to children if they correctly responded to multiple choice questions (Watters 2015). These teaching machines were deeply informed by the psychological science of behaviourism popular at the time which assumed if children were rewarded for successful completion of tasks that this would reinforce—or 'condition'-their positive learning behaviours (Selwyn 2011).

ClassDojo combines behaviourist reward systems with behavioural surveillance in ways which are aimed at subtly modifying the classroom behaviours of children. A critical commentary in the New York Times in 2014 raised concerns about ClassDojo being used to award 'virtual badges for obedience' (Singer 2014). ClassDojo's founders even issued a public response detailing what the paper 'got wrong,' emphasizing its use for positive behaviour reinforcement. Yet positive reinforcement has always been the aim of behavourist conditioning techniques, and assumes particular norms of behaviour that are inevitably contested. ClassDojo's emphasis on positive behaviour management reinforces this behaviourist trend. Behaviourism also focuses on 'observable' behaviours; ClassDojo makes behavioural observation into a real-time process of data collection. By allowing teachers to display children's progress alongside each other, it also encourages behavioural competition and group surveillance. In a rare empirical study of ClassDojo, Burger (2015: 186) found that: 
students are influenced by the results associated with their behaviors. ... [W] hen a student receives a positive point, the other students in the classroom recognize what that student did to earn the positive point. They then think about what they have to do to replicate that behavior in order to receive the same reward/benefit.

At the same time, it invites parents to inspect and police their child's progress. It is, ultimately, a behaviourist surveillance machine for the classroom that encourages and rewards compliance with behavioural norms that have been derived from contested psychological categories. In this sense, it is consistent with recent 'psycho-polices' that have authorized 'the extension of statesanctioned surveillance to psychological characteristics' across the public sector (Friedli \& Stearn 2015: 43). It enables educators to identify ostensible psychological barriers to learning and to inculcate social and emotional attributes and attitudes that are seen as appropriate to student progress.

\section{Mindset modification}

The emergence of psycho-policy in education is exemplified by the rapid diffusion of new ideas about 'character development' and 'growth mindsets' on both sides of the Atlantic (Reynolds \& Birdwell 2015), not least through the interventions and reports of influential global organizations such as the OECD (2015) and World Economic Forum (2016). This is at a time when US education policymakers, following the 2015 introduction of the Every Student Succeeds Act, are demanding more non-academic and non-cognitive measures of school performance. In several Californian districts, measures of 'social-emotional skills' including 'grit' and 'growth mindsets' are already being developed and trialed, with strong governmental support from the US Department of Education, which is seeking new accountability tools to quantify and measure school performance (Adams 2014; Zernike 2016).

ClassDojo is the most popular, and rapidly diffusing, educational application of these ideas. Its founding directors explicitly describe its purpose as promoting 'character development' in schools and it is underpinned by particular psychological concepts from character research. Its website approvingly cites the journalist Paul Tough, author of two books on promoting 'grit' and 'character' in children (Tough 2016), and is informed by character research conducted with the US network of KIPP charter schools (Knowledge is Power Program). One of its staff, Kalen Gallagher, formerly taught at a KIPP school, and actively channels the KIPP philosophy into the ClassDojo device (Knott 2012). KIPP's approach focuses on 'the development of character' and is itself grounded in the positive psychology of Martin Seligman, author of texts on 'authentic happiness' and 'flourishing'. Building on this psychological work, KIPP focuses on 'seven highly predictive character strengths that are correlated to leading engaged, happy and successful lives: zest, grit, optimism, self-control, gratitude, social intelligence, and curiosity' (http://www.kipp.org/our-approach/character). ClassDojo's own categories of positive behaviour reflect and reinforce this emphasis on character development, happiness, perseverance and grit. Horn (2012) has critiqued KIPP as a form of 'cultural sterilization' and 'corporate education reform,' referring specifically to its emphasis on students taking responsibility for the improvement of any 'shortcomings' of character and grit. He has subsequently described 
ClassDojo as 'digitized and cutesy' device that, by following KIPP, 'uses children to become complicit in their own monitoring and labeling’ (Horn 2014).

ClassDojo co-founder and chief executive officer Sam Chaudhary has described its emphasis on character development in more upbeat terms:

'Education goes beyond just a test score to developing who the student is as a person-including all the character strengths like curiosity, creativity, teamwork and persistence. ... We shouldn't just reduce people to how much content they know; we have to develop them as individuals.' (Mead 2013)

Chaudhary goes on to describe the 'people whose example shapes our work,' including:

\footnotetext{
'thought leaders in the field of behavior and building character: James Heckman and his work on power of building character early in life; Angela Duckworth's work on persistence and grit; Carol Dweck's work on the growth mindset and the praise we give kids. Doug Lemov and Lee Canter talk about the principles that ClassDojo is built on.' (Mead 2013)
}

These influences are important to understanding ClassDojo as a conduit for popular psychological concepts into the pedagogic spaces of schools. James Heckman, a former recipient of a Nobel prize, is professor of behavioural economics at the University of Chicago, and an influential thought leader on character education. His own website, The Heckman Equation, focuses on the economics of human potential and particularly emphasizes 'the early development of cognitive and social skills in children' (http://heckmanequation.org/heckmanequation). Angela Duckworth is a professor of psychology at the University of Pennsylvania, where she runs The Duckworth Lab to investigate 'grit' and 'self-control.' According to its website, 'grit is the tendency to sustain interest in and effort toward very long-term goals,' while 'self-control is the voluntary regulation of behavioral, emotional, and attentional impulses'; together, grit and self-control are 'conceptualized as dimensions of human character, social and emotional competency, and non-cognitive human capital' (https://sites.sas.upenn.edu/duckworth/pages/research-statement). Duckworth has published research with Martin Seligman on these aspects of character, and authored Grit: The power of passion and perseverance. Another named influence on ClassDojo is Doug Lemov, founder of the 'Teach Like a Champion' training program, who 'spent his early career putting his faith in market forces, building accountability systems meant to reward high-performing charter schools and force the lower-performing ones to either improve or go out of business,' before turning his attention to classroom management training techniques (Green 2010). Lee Canter has published Assertive Discipline: Positive behaviour management for today's classrooms. Together, these 'thought leaders,' as ClassDojo's founder describes them, represent an alliance of psychological and economic conceptualizations of teaching and learning.

The most significant influence on ClassDojo, though, is Carol Dweck and the popularization of her concept of 'growth mindsets.' In January 2016 ClassDojo announced a partnership with the Project for Education Research That Scales (PERTS), an applied research center at Stanford University (see http://www.prnewswire.com/news-releases/stanford-perts-lab-and-classdojopartner-to-bring-growth-mindset-to-every-classroom-300205920.html). PERTS is the intellectual 
home of the theory of growth mindsets and is led by Carol Dweck, whose research in this area extends back to 1970s psychological investigations of 'learned helplessness' and 'attribution theory,' much of which she worked on with Martin Seligman (Dweck 2015). Building on these areas, Dweck's concept of growth mindsets focuses on the ways people differently perceive their intelligence: some people have an 'entity theory of intelligence,' as something that is fixed and unchangeable; other possess an 'incremental theory of intelligence' whereby they perceive intelligence as subject to change, which can be improved through hard work and effort (Dweck 2015). People with an incremental theory of intelligence, or a growth mindset, are more likely to seek out intellectual challenges and respond positively to complex tasks.

Dweck's books Mindset: The new psychology of success and Self-Theories: Their role in motivation, personality and development, have popularized the concept and form the intellectual backbone to the research conducted at PERTS (https://www.perts.net/about):

\footnotetext{
Teaching people to have a 'growth mind-set,' which encourages a focus on 'process' rather than on intelligence or talent, produces high achievers in school and in life. Parents and teachers can engender a growth mind-set in children by praising them for their persistence or strategies (rather than for their intelligence), by telling success stories that emphasize hard work and love of learning, and by teaching them about the brain as a learning machine. (Dweck 2015)
}

Dweck has also previously cofounded the spin-out company Mindset Works to disseminate training materials and resources to schools on a commercial basis, with support from the US Department of Education's Institute of Education Sciences. Dweck argues that direct instruction about growth mindsets can help people to see and understand their own intelligence in ways that are more malleable. Her Mindset Works training resources 'You Can Grow Your Brain' and 'Brainology' teach the lesson 'that the brain is like a muscle that gets stronger with use and that learning prompts neurons in the brain to grow new connections. From such instruction, many students began to see themselves as agents of their own brain development' (Dweck 2015). In 2013 the US Department of Education Office of Technology strongly promoted Dweck's findings on growth mindsets in the recommendations of its report Promoting Grit, Tenacity and Perseverance (Schechtman et al. 2013). Dweck was listed among the 'expert informants' of the report, along with Angela Duckworth, Paul Tough, and Mitch Brenner of the KIPP charter schools network, among others. In addition, ClassDojo was directly promoted in the report as 'a classroom management tool that helps teachers maintain a supportive learning environment and keep students persisting on task in the classroom,' allowing 'teachers to track and reinforce good behaviors for individual students, and get instant reports to share with parents or administrators' (Schechtman et al. 2013: 68).

The partnership between ClassDojo and PERTS takes the form of a series of short animations that help explain the growth mindsets idea for teachers and learners themselves. The videos are basically high-production updates of the Mindset Works instructional resources. Five initial videos were launched on the ClassDojo website in January 2016, with more releases later in April. By late summer 2016 the ClassDojo website included claims the videos had been viewed over 15 million times. The press release upon launch stated: 
Because it is already used in half of U.S. schools, ClassDojo provides an unprecedented opportunity to seamlessly bring breakthrough, evidence-based educational practices to millions of teachers and classrooms.

'Growth mindset is a phenomenally important idea that's been proven to benefit children well into the future,' said Liam Don, co-founder and Chief Product Officer at ClassDojo. 'In developing our "Big Ideas" series we wanted to make these transformative ideas easy for teachers to incorporate into their classroom, and delightful for students. Our partnership with Stanford PERTS is a good example of how technology can help make big ideas accessible and exciting for students in every classroom. We're thrilled to share this "Big Idea" with our community of teachers- the first of more to come!'

Over the course of the animations on the 'Big Ideas' section of the ClassDojo site, the Dojo monster character learns to develop an adaptive growth mindset rather than a fixed mindset. In the process, he learns about the new sciences of the brain. Underlying the videos is the assumption that neuroscience has unlocked the secrets of learning. They present the brain as a malleable 'muscle' that can constantly grow and adapt as it is put to the task of addressing challenging problems.

The presentation of the brain as a muscle in ClassDojo is related to the recent popularization of neuroscience concepts of 'neuroplasticity,' where the brain is seen as constantly adapting to the social environment, and part of 'the dispersal of neurobiological language, imagery, symbolism and rhetoric within formal and informal learning environments' (Busso \& Pollack 2015: 169). Rather than being seen as a structurally static organ, the brain has been reconceived as dynamic, with new neural pathways constantly forming through adaptation to environmental stimuli (Pickersgill 2013). However, as Pykett (2015: 135) notes, 'the fundamental problem of applying neuroscientific insight' to educational practice 'is that neuroscience can only study pre-conceived psychological theories, not actual behaviour.' In other words, the appeal to neuroscience is often used to confirm pre-existing psychological concepts and theorizations of behaviours. In the case of ClassDojo's partnership with PERTS, psychological concepts of growth mindsets underpin its translation of neuroscientific notions of neuroplasticity.

The partnership with PERTS also positions ClassDojo as a large-scale site for growth mindsets research. PERTS executive director Dave Paunesku has claimed that because ClassDojo can track engagement with their videos and tools, the PERTS researchers can gather new insights into how the growth mindset message changes student engagement levels, claiming that 'We want teachers to think about the kind of norms they want to set in the classroom so that growth mindset is integrated in it' (van Dijk 2016). ClassDojo is a key vehicle for the continuing propagation of the mindsets movement into schools, with its data being used by PERTS researchers to investigate learners' growth mindsets. This development appears to make ClassDojo's 30 million child users into research subjects in a massive experiment in mindset modification. Because their brains are conceived through the idea of neuroplasticity and their mindsets conceptualized as adaptive, the children using ClassDojo are treated as behaviourally modifiable through classrooms in which growth mindset norms have been integrated.

ClassDojo reconceptualizes the child user in terms of popular psychological and neuroscientific classifications. It then enables teachers to measure the child according to those categories, and 
award a value to the child through points and rewards. It encourages children to see and understand themselves in terms of the plasticity of their brain muscles and the adaptivity of their mindsets. These scientific classifications of the child are encoded into the ClassDojo classroom tool. In so doing, it displaces a focus on critical educational questions of pedagogy and curriculum, emphasizing the pursuit of individual improvement while ignoring the societal structures that impact on children's education.

\section{Innovation investment}

By focusing on personal improvement over structural problems, ClassDojo reinforces the emphasis on 'technical fixes' and 'solutionism' that preoccupies Silicon Valley technology companies (Morozov 2013). Psychological initiatives, especially those derived from behavioural economics, have been popularized on Silicon Valley's technology campuses as ways of optimizing employees' attitudes and behaviours. Popular Silicon Valley training initiatives translate psychological and behavioural insights into training curricula that enable delegates to 'fix personal problems' by 'learning to notice behaviors and assumptions that we're often barely conscious of; feeling around to understand the roots of those behaviors; and then using those insights to create change' (Kahn 2016). Silicon Valley subscribes to the technocratic ideology that all problems - including human behavioural problems — can be solved with digital technologies (Selwyn 2016), and that the role of education is to 'invest' in making people more entrepreneurial and innovative (Ferenstein 2015). In other words, Silicon Valley is becoming a site of psychological experimentation as well as technical innovation.

As a direct product of the psychologized perspective of Silicon Valley, ClassDojo exemplifies the increasingly close-knit relationship between certain forms of psychological research and technology development. Its partnership with PERTS at Stanford University is particularly indicative. Located within the valley itself, Stanford has 'not only witnessed, but also notoriously housed, some of the most celebrated innovations in Silicon Valley' (Trikha 2015). The close relationship between Stanford and Silicon Valley is being continued in the ed-tech sector, such as through the Stanford Lytics Lab, which has begun applying new data analytics techniques to the measurement of non-cognitive learning factors including perseverance, grit, emotional state, motivation and self-regulation (Pea 2014). Stanford is also the home of the Persuasive Technologies Lab, which focuses on the development of 'machines designed to influence human beliefs and behaviors' across domains including health, business, safety, and education (http://captology.stanford.edu/invisible-resource/human-behavior.html). Its researchers apply psychological insight about human behaviour to the design of technology products. Many of Silicon Valley's most successful engineers and designers are alumni of the lab, trained to design technologies to create 'habit-forming products,' otherwise known as 'persistent routines' or 'behavioral loops' (Weisberg 2016). As a behavioural reinforcement app, ClassDojo can be understood as a persuasive technology designed to routinize particular forms of behaviour, particularly those that are explained in terms of psychological concepts of growth mindsets and character development.

The partnership between ClassDojo and the PERTS growth mindsets laboratory needs to be seen in this context. Through its partnership with PERTS and Carol Dweck, ClassDojo is closely 
networked into both the technical and scientific expert practices of Stanford. These activities reflect the Silicon Valley ideology of technological idealism and its investment in 'making people awesome' (Ferenstein 2015). This is characterized by Neff (2012: 17) as 'venture labor,' or the 'form of investment' that entrepreneurial workers in the technology sector make in their own skills and personal development.For example, Dweck (2015) has explicitly extended the growth mindset concept to business management, arguing that 'managers with a growth mind-set see themselves as works-in-progress and understand that they need feedback to improve, whereas bosses with a fixed mind-set are more likely to see criticism as reflecting their underlying level of competence.' Dweck herself has given a growth mindsets talk at Google on hiring candidates who see their skills and talents as malleable, part of Google's massive psychological experimentations in 'employee performance optimization' (Duhigg 2016). The growth mindsets concept is therefore being promoted by PERTS in the context of the skills and talents of entrepreneurship, willingness to take on challenges and risks, and the capacity to learn from mistakes. Exactly the same message about growth mindsets is presented in the videos produced by ClassDojo and PERTS. This makes ClassDojo the perfect educational technology for fostering the entrepreneurial, adaptive learning mindsets promoted by the high-tech culture of Silicon Valley innovation.

As part of the education startup sector, ClassDojo emblematizes the current intersections of Silicon Valley venture investment and venture labour with the new sciences of psychology emerging from Stanford. It seeks to employ new psychological and neuroscientific concepts and insights — such as growth mindsets — as a way of 'investing' in people and solving the problem of classroom behaviour. It also basically treats classroom behaviour technocratically as an information problem, in the sense that if more data is available about classroom behaviour then it will be easier to solve the problem. Through these networks and translations, ClassDojo is becoming a vehicle for the growth mindsets movement coming out of Stanford's PERTS lab, and is also related to the rapid rise of a governmental agenda around measuring children's socialemotional skills, as well as behaviour modification training programs and persuasive technologies emerging from the application of psychological and behavioural theory in Silicon Valley. It is making contested psychological and neuroscientific ideas about malleable mindsets and neuroplasticity into taken-for-granted categories, and by encoding them as norms in the black box of the ClassDojo device itself, making these categories into measurements by which children may be surveilled, valued, and made amenable to behavioural modification through persuasive technologies at global scale.

\section{Psycho-policy in schools}

By translating Silicon Valley's emphasis on personal improvement and persuasive technologies together with the psychological emphasis on social-emotional learning, character education and growth mindsets, ClassDojo has become part of a network of technologies and discourses which is speeding up the diffusion of governmental behavior change aspirations into schools. Behavioural sciences insights_-which emerge from the synthesis of psychological, neuroscientific and economics theories of human behaviour-are increasingly being treated by governments in both north America and Europe as the basis for 'psycho-policy' design and state intervention (Friedli \& Stearn 2015). The 'behaviour change agenda' is based on the assumption 
that human behaviour is largely habitual and predictable, and therefore manipulable, and has 'led to the gradual formation of new governmental programmes that seek to guide and compensate for the behaviours of the sub-optimal citizen' (Jones, Pykett \& Whitehead 2013: 3). Friedli and Stearn (2015: 42), for example, have documented how governmental adoptions of psychology and behavioural economics have resulted in state strategies of 'psycho-compulsion, defined as the imposition of psychological explanations ... together with mandatory activities intended to modify beliefs, attitude, disposition or personality.'

According to a recent report on behavioural economics implications for education, the field attempts to integrate research from psychology, neuroscience, and economics to help develop policies that address shortcomings in individuals' decision-making processes, and acknowledges that 'our brain's architecture may lead to suboptimal outcomes' (Lavecchia, Liu \& Oreopoulos 2014: 4). The authors particularly note the problem of getting children to 'invest' in their own education, and suggest that behavioural economics insights could be employed in classroom interventions since, it claims, 'education itself may affect brain development' (Laveccia et al. 2014: 5). The report highlights Carol Dweck's work on growth mindsets, linking her notion that 'the brain is malleable and that through hard work, intelligence can be improved' to the idea that students might be 'nudged' through small interventions aimed at 'decreasing the likelihood that small failures cause students to believe that academic success is unachievable' (Lavecchia et al. 2014: 67). The same key messages, and support for both the growth mindsets concept and ClassDojo, run through the US Department of Education report Promoting Grit, Tenacity and Perseverance (Schechtman et al. 2013). As the journalist Tough (2016) puts it in his review of strategies to promote non-cognitive learning and character development, classroom environments that 'convey deep messages-perhaps implicitly or even subliminally_about belonging, connection, ability, and opportunity' exert 'a profound impact on students' psychology, and thus on their behavior.'

As part of the current movement towards 'quantifying growth in non-cognitive skills' (Adams 2014) that characterizes governmental concerns with social and emotional learning in schools, ClassDojo represents a successful technical instantiation within education of the behaviour change agenda which has become part of many aspects of public policy and state strategy in recent years. As an ed-tech example of a persuasive technology, it encourages certain norms of behavioural comportment derived from psychological and neuroscientific forms of expertise, makes the acquisition of such behaviours into a game through its habit-forming technology, and reinforces them through the distribution of rewards. As such, ClassDojo is not merely a tool for measuring behaviours, but a technology of psycho-compulsion and behaviour modification that encourages teachers to award positive value and feedback to behaviours deemed appropriate to developing a growth mindset. With the 2016 announcement of its 'schoolwide' features, ClassDojo is also positioning itself as a communication and presentation platform for schools, at precisely the same time they are coming under new accountability pressures to quantify growth in the nonacademic dimensions of learning.

Significantly, the ClassDojo business model positions it perfectly to maximize the potential of this synthesis of positive psychology and school accountability. Thanks to its global reach, 
ClassDojo has amassed a significant database of information about children and teachers. It has recently proposed that it might generate revenue by selling media content to teachers and schools (such as follow-ups to its growth mindsets series) and that it might sell premium features to schools and school districts. ClassDojo is therefore seeking to insert itself into existing political structures and accountability systems by selling education authorities the data required to measure and rate schools in terms of their progress in developing students' non-academic learning. With its massive datasets from schools across the US and further afield, ClassDojo is well positioned to provide these data, which are likely to be welcomed by schools and education authorities alike as ways of monitoring their development toward new psychological goals, and changing their organizational behaviours if required.

In all of these ways, ClassDojo has become a key technology for speeding up the diffusion and enactment of behavioural science and governmental behavior change ambitions in education. Further empirical work is required to trace its interconnection with sprawling networks of other actors, discourses and technologies, and to fully analyze ClassDojo as part of a 'new generation of fast-policy "models" and "best practices" that is 'being forged across transnational expert networks and communities of practice' and becoming part of 'governance regimes' (Peck \& Theodore 2015: 7). As this initial survey of the device and its networks has shown, ClassDojo is ideally positioned as a fast-policy model for the diffusion and enactment within the pedagogic routines of the classroom of psycho-policy agendas related to social and emotional learning; it serves as a best practice model highlighted both by scientific experts such as Dweck and in government reports, and that is proliferating in the communities of practice of teachers; and it is becoming a key technique of psycho-compulsion by which schools can promote the student behaviours according to which they may in future be measured and governed.

\section{Conclusion}

Through the dynamics of translation, ClassDojo has become a stabilized object of a network of scientific, governmental, technical and economic innovations and the shared vocabularies, theories and explanations of positive psychologists, Silicon Valley entrepreneurs, government education departments, and global education policy influencers. The ClassDojo app and platform has become a fast-policy model for government at a distance, whereby governmental goals around the measurement and management of students' non-cognitive social-emotional learning are reinforced at arms-length by its use as a persuasive technology of behavioural 'nudging' in the classroom. In this sense, it also exemplifies the rise of behavioural psychopolicies that focus on both the surveillance of psychological characteristics and on the design of psycho-compulsion interventions intended to modify behaviours and emotions to meet specific measurable goals (Friedli \& Stearn 2015).

Though there is nothing inherently new about educational technologies being developed to enact government agendas, ClassDojo represents a particularly arresting contemporary nexus of governmental, psychological, commercial and technical developments requiring further analysis. It is a persuasive technology that enables schools and teachers to promote and reward behaviours that indicate students' social-emotional learning, growth mindset and character development; in turn these are categories being promoted globally by policy influencers such as 
the OECD and WEF, and by which schools in the future may be measured and held accountable as they become embedded in governmental psycho-policies. ClassDojo's global success beyond its initial popularity in the US is tightly bound to the rapid diffusion of the social and emotional learning agenda, a notable current example of a fast policy still in motion. In the OECD report, it is claimed that "While everyone acknowledges the importance of social and emotional skills, there is often insufficient awareness of "what works" to enhance these skills and efforts made to measure and foster them' (OECD 2015: 3). ClassDojo’s global popularity attests to the speedingup of a transnational political emphasis on the psychological measurement and management of children's social and emotional lives, and is increasingly viewed as a technical exemplar of 'what works' and a 'best practice' in the promotion of new psychological explanations and interventions in education.

\section{References}

Adams, J. M. 2014. Measuring a 'growth mindset' in a new school accountability system. EdSource, 5 May 2014: http://edsource.org/2014/measuring-a-growth-mindset-in-a-new-school-accountability-system/63557

Ball, S.J. 2016. Following policy: networks, network ethnography and education policy mobilities. Journal of Education Policy. DOI: 10.1080/02680939.2015.1122232

Burger, M. 2015. The Perception of the Effectiveness of ClassDojo in Middle School Classrooms: A Transcendental Phenomenological Study. Unpublished doctoral dissertation, Liberty University. Available online: http:/ / digitalcommons.liberty.edu/cgi/viewcontent.cgi?article=2110\&context $=$ doctoral

Busso D, Pollack C. 2015. No brain left behind: Consequences of neuroscience discourse for education. Learning, Media, and Technology 40 (2):168-186.

Duckworth, A.L. \& Yeager, D.S. 2015. Measurement Matters: Assessing Personal Qualities Other Than Cognitive Ability for Educational Purposes. Educational Researcher 44, no. 4: 237-251.

Duff, A.S. 2016. Rating the revolution: Silicon Valley in normative perspective. Information, Communication and Society. DOI: $10.1080 / 1369118 X .2016 .1142594$

Duhigg, C. 2016. What Google learned from its quest to build the perfect team. New York Times Magazine, 28 February 2016: http://www.nytimes.com/2016/02/28/magazine/what-google-learned-from-its-quest-to-buildthe-perfect-team.html

Dweck, C.J. The Secret to Raising Smart Kids. Scientific American, 1 January 2015: http://www.scientificamerican.com/article/the-secret-to-raising-smart-kids1/

EEF (Education Endowment Foundation). 2016. Social and Emotional Learning Strategies. https://educationendowmentfoundation.org.uk/resources/early-years-toolkit/social-and-emotional-learningstrategies

Empson, R. 2012. ClassDojo Lands \$1.6M From Paul Graham, Ron Conway To Help Teachers Control Their Classrooms. TechCrunch, 15 August 2012: http://techcrunch.com/2012/08/15/classdojo-launch-seed-funding/

Fenwick, T. \& Edwards, R. 2010. Actor-Network. Theory in Education. London: Routledge.

Ferenstein, G. 2015. The Age of Optimists: A quantitative glimpse of how Silicon Valley will transform politics and everyday life. Available online: https://medium.com/the-ferenstein-wire/silicon-valley-s-political-endgame-summarized$1 \mathrm{f} 395785 \mathrm{f} 3 \mathrm{c} 1$

Friedli, L. \& Stearn, R. 2015. Positive affect as coercive strategy: conditionality, activation and the role of psychology in UK government workfare programmes. Medical Humanities 41: 40-47.

Green, E. 2010. Building a Better Teacher. New York Times Magazine, 2 March 2010: http://www.nytimes.com/2010/03/07/magazine/07Teachers-t.html?ref=magazine\&_r=0 
Horn, J. 2012. Paul Tough, KIPP, and the 'Science' of Cultural Sterilization. Schools Matter, 7 October 2012: http://www.schoolsmatter.info/2012/10/paul-tough-kipp-and-science-of-cultural.html

Horn, J. 2014. ClassDojo: Another Insecure Child Labeling, Shaming, and Tracking Device. Schools Matter, 17 November 2014: http://www.schoolsmatter.info/2014/11/classdojo-another-insecure-chilld.html

Jones, R., Pykett, J. \& Whitehead, M. 2013. Changing Behaviours: On the rise of the psychological state. Cheltenham: Edward Elgar.

Kahn, J. 2016. The Happiness Code. New York. Times Magazine, 14 January 2016: http://www.nytimes.com/2016/01/17/magazine/the-happiness-code.html

Knott, J. 2012. ClassDojo-more than simple behaviour tracking. Educational Technology and Change, 19 January 2012 : http:/ / etcjournal.com/2012/01/19/classdojo-more-than-simple-behavior-tracking/

Kolodny, L. 2016. ClassDojo raises $\$ 21$ million for app to make parent-teacher meetings obsolete. TechCrunch, 15 April 2016: http:/ / techcrunch.com/2016/04/15/classdojo-raises-21-million-for-app-to-make-parent-teachermeetings-obsolete/

Lavecchia, A.M., Liu, H. \& Oreopoulos, P. 2014. Behavioral Economics of Education: Progress and Possibilities. National Bureau of Economic Research, Working Paper 20609: http://www.nber.org/papers/w20609.pdf

Lee, T.B. \& Ferenstein, G. 2016. 'Libertarian but very pro-government': the distinctive ideology of Silicon Valley. Vox, 19 February 2016: http://www.vox.com/2016/2/19/11057836/silicon-valley-democrat-explained

Lewis, S. \& Hogan, A. 2016. Reform first and ask questions later? The implications of (fast) schooling policy and 'silver bullet' solutions. Critical Studies in Education: http://dx.doi.org/10.1080/17508487.2016.1219961

Mead, S. 2013. Profile of ClassDojo Founders Sam Chaudhury and Liam Don. Education Week, 11 June 2013: http://blogs.edweek.org/edweek/sarameads_policy_notebook/2013/06/sam_chaudhary_and_liam_don_cofounders_classdojo.html

Miller, P. \& Rose, N. 2008. Governing the Present: Administering economic, social and personal life. Cambridge: Polity.

Morozov, E. 2013. To Save Everything, Click Here: Technology, solutionism and the urge to fix problens that don't exist. London: Allen Lane.

Neff, G. 2012. Venture Labor: Work and the Burden of Risk in Innovative Industries. London: MIT Press.

OECD (Organization for Economic Cooperation and Development). 2015. Skills for Social Progress: The Power of Social and Emotional Skills. OECD Skills Studies, OECD Publishing: http://dx.doi.org/10.1787/9789264226159en

Pea, R. 2014. A report on building the field of learning analytics for personalized learning at scale. Stanford: Stanford University.

Peck, J. \& Theodore, N. 2015. Fast Policy: Experimental statecraft at the thresholds of neoliberalism. London: University of Minnesota Press.

Pickersgill M. 2013. The social life of the brain: Neuroscience in society. Current Sociology 61 (3): 322-340.

Popkewitz, T.S. 2012. Numbers in Grids of Intelligibility: making sense of how educational truth is told. In Educating for the Knowledge Economy? Critical perspectives, edited by H. Lauder, M. Young, H. Daniels, M. Balarin \& J. Lowe, 169-191. Abingdon: Routledge.

Pykett, J. 2015. Brain Culture: Shaping policy through neuroscience. Bristol: Policy Press.

Reynolds, L. \& Birdwell, J. 2015. Mind over Matter. London: Demos.

Rose, N. 1996. Inventing Our Selves: Psychology, power and personhood. Cambridge: Cambridge University Press.

Selwyn, N. 2011. Education and Technology: Key issues and debates. London: Continuum.

Selwyn, N. 2016. Is Technology Good for Education? Cambridge: Polity.

Shechtman, N., DeBarger, A.H., Dornsife, C., Rosier, S. \& Yarnall, L. 2013. Promoting Grit, Tenacity and Perseverance: Critical factors for success in the $21^{\text {st }}$ century. U.S. Department of Education, Office of Educational Technology. 
Singer, N. 2014. Privacy Concerns for ClassDojo and Other Tracking Apps for Schoolchildren. New York Times, 16 November 2014: http://www.nytimes.com/2014/11/17/technology/privacy-concerns-for-classdojo-and-othertracking-apps-for-schoolchildren.html

Tough, P. 2016. How kids learn resilience. The Atlantic, June 2016:

http://www.theatlantic.com/magazine/archive/2016/06/how-kids-really-succeed/480744/

Trikha, R. 2015. The Interdependency of Stanford and Silicon Valley. TechCrunch, 4 September 2015: http://techcrunch.com/2015/09/04/what-will-stanford-be-without-silicon-valley/

van Dijk, P.E.E. 2016. ClassDojo and PERTS launch growth mindset toolkit. The Stanford Daily, 17 February 2016: http://www.stanforddaily.com/2016/02/17/classdojo-and-perts-launch-growth-mindset-toolkit/

Watters, A. 2015. The Automatic Teacher. Hack Education, 4 February 2015: http://hackeducation.com/2015/02/04/the-automatic-teacher

WEF (World Economic Forum). 2016. New Vision for Education: Fostering Social and Emotional Learning through Technology. http://www3.weforum.org/docs/WEF_New_Vision_for_Education.pdf

Weisberg, J. We are hopelessly hooked. The New York Review of Books, 25 February 2016: http://www.nybooks.com/articles/2016/02/25/we-are-hopelessly-hooked/

Whitson, J. R. 2013. Gaming the quantified self. Surveillance \&o Society 11 (1): 163-176.

Williamson, B. 2016. Silicon startup schools: Technocracy, algorithmic imaginaries and venture philanthropy in corporate education reform. Critical Studies in Education: http:/ /dx.doi.org/10.1080/17508487.2016.1186710

Zernike, K. 2016. Testing for Joy and Grit? Schools Nationwide Push to Measure Students' Emotional Skills. New York Times, 29 February 2016: http:/ /www.nytimes.com/2016/03/01/us/testing-for-joy-and-grit-schoolsnationwide-push-to-measure-students-emotional-skills.html 